\title{
(6) OPEN ACCESS \\ Admission to hospital for bronchiolitis in England: trends over five decades, geographical variation and association with perinatal characteristics and subsequent asthma
}

\author{
Christopher A Green, ${ }^{1}$ David Yeates, ${ }^{2}$ Allie Goldacre, ${ }^{2}$ Charles Sande, ${ }^{1}$ \\ Roger C Parslow, ${ }^{3}$ Philip McShane, ${ }^{3}$ Andrew J Pollard, ${ }^{1}$ Michael J Goldacre ${ }^{2}$
}

\begin{abstract}
- Additional material is published online only. To view please visit the journal online (http://dx.doi.org/10.1136/ archdischild-2015-308723).

1 Department of Paediatrics, University of Oxford, and the NIHR Oxford Biomedical Research Centre, UK ${ }^{2}$ Unit of Health-Care Epidemiology, Nuffield Department of Population Health, University of Oxford, Oxford, UK

${ }^{3}$ Division of Epidemiology and Biostatistics, University of Leeds, Leeds, UK
\end{abstract}

\section{Correspondence to} Dr Christopher A Green, Oxford Vaccine Group, Centre for Clinical Vaccinology \& Tropical Medicine, Churchill Hospital, Oxford OX3 7LE, UK christopher.green@paediatrics. ox.ac.uk

Received 3 April 2015 Accepted 28 July 2015 Published Online First 4 September 2015

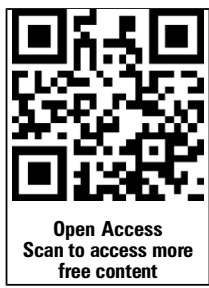

\section{SLinked}

- http://dx.doi.org/10.1136/ archdischild-2015-309452

\section{CrossMark}

To cite: Green $C A$,

Yeates D, Goldacre A, et al. Arch Dis Child

2016:101:140-146.

\section{ABSTRACT}

Background Admission of infants to hospital with bronchiolitis consumes considerable healthcare resources each winter. We report an analysis of hospital admissions in England over five decades.

Methods Data were analysed from the Hospital InPatient Enquiry (HIPE, 1968-1985), Hospital Episode Statistics (HES, 1989-2011), Oxford Record Linkage Study (ORLS, 1963-2011) and Paediatric Intensive Care Audit Network (PICANet, 2003-2012). Cases were identified using International Classification of Diseases (ICD) codes in discharge records. Bronchiolitis was given a separate code in ICD9 (used in England from 1979). Geographical variation was analysed using Local Authority area boundaries. Maternal and perinatal risk factors associated with bronchiolitis and subsequent admissions for asthma were analysed using recordlinkage.

Results All-England HIPE and HES data recorded 468138 episodes of admission for bronchiolitis in infants aged <1 year between 1979 and 2011. In 2011 the estimated annual hospital admission rate was 46.1 (95\% Cl 45.6 to 46.6 ) per 1000 infants aged <1 year. Between 2004 and 2011 the rates rose by an average of $1.8 \%$ per year in the all-England HES data, whereas admission rates to paediatric intensive care changed little (1.3 to 1.6 per 1000 infants aged $<1$ year). A fivefold geographical variation in hospital admission rates was observed. Young maternal age, low social class, low birth weight and maternal smoking were among factors associated with an increased risk of hospital admission with bronchiolitis.

Conclusions Hospital admissions for infants with bronchiolitis have increased substantially in recent years. However, cases requiring intensive care have changed little since 2004.

\section{INTRODUCTION}

Care of infants with bronchiolitis places a substantial burden on paediatric hospital resources each winter. Infants aged $<1$ year with bronchiolitis account for $18 \%$ of all paediatric admissions. ${ }^{1}$ Infection by respiratory syncytial virus (RSV) is responsible for almost $80 \%$ of cases. ${ }^{2}$ Most cases are not severe and can be managed conservatively at home, but approximately $30 \%$ of primary infections involve the lower respiratory $\operatorname{tract}^{3}$ and supportive care by hospital admission is warranted if feeding or respiration become compromised.

\section{What is already known}

- Bronchiolitis admissions are a great burden to paediatric hospital resources each winter in industrialised healthcare systems.

- Hospitalisation rates for bronchiolitis rose significantly in the USA and Canada in the 1990s.

\section{What this study adds}

- The annual average episode-based admission rate for bronchiolitis rose sevenfold between 1979 and 2011.

- Since 2004, the estimated all-England annual average hospital admission rate rose by an average of $1.8 \%$ each year.

- Bronchiolitis admission rates to paediatric intensive care did not change, implying that increasing hospital admission rates have not been driven by any change in disease severity.

- Record-linkage shows that maternal and perinatal factors are important risk factors for developing severe bronchiolitis and the need for hospitalisation in infancy.

Two-thirds of infants have an RSV infection in the first year of life, ${ }^{3} 2 \%-3 \%$ of primary infections will require admission to hospital ${ }^{4}{ }^{5}$ and $2 \%-6 \%$ of these admissions need management on paediatric intensive care units (PICUs). ${ }^{15-7}$ Bronchiolitis early in infancy is associated with a higher likelihood of developing wheeze and asthma later in life, and a causal association with asthma remains the subject of enquiry. ${ }^{8-10}$ Worldwide, RSV disease in children under the age of 5 years accounts for 33.8 million lower respiratory infections and 3.4 million hospitalisations. Access to mechanical ventilation on PICUs has helped maintain a low mortality in industrialised nations $(0 \%-1.5 \%$ in otherwise healthy infants with RSV). ${ }^{11}$ Globally, an estimated 66 000-199 000 RSV-related deaths occur annually, almost exclusively in resource-poor areas, with RSV being second only to malaria in all-cause infant mortality between 1 and 12 months of age. ${ }^{12}{ }^{13}$ 
Prematurity, bronchopulmonary dysplasia, congenital heart disease, immunodeficiency, cerebral palsy and Down's syndrome are recognised risk factors for severe bronchiolitis, ${ }^{14-16}$ but $50 \%-80 \%$ of emergency admissions occur in otherwise healthy infants born at term. 1516

There is evidence of a rise in admission rates for bronchiolitis occurring over time in the USA and Canada during the 1990s. ${ }^{17} 18$ We report an analysis of hospital admissions of infants with bronchiolitis in England over five decades. The main objective was to describe a time-trend analysis of admission to hospitals and to PICUs in England. Additional objectives were to map geographical and socioeconomic variation in hospital admission rates. Record-linked data were used to quantify social, maternal and perinatal factors that confer a risk of admission for bronchiolitis, and to measure the risk of later admission for asthma after bronchiolitis.

\section{METHODS}

We used discharge codes in any diagnostic position on hospital admission datasets that are routinely collected in England including the Hospital In-Patient Enquiry (HIPE), Hospital Episode Statistics (HES) and Oxford Record Linkage Study (ORLS). Hospital admissions for bronchiolitis were identified using International Classification of Disease (ICD) codes J21.0, $\mathrm{J} 21.1, \mathrm{~J} 21.8$ and J21.9 in the 10th revision of the ICD (ICD10, 1999-2011) and 466.1 in ICD9 (1979-1998). In the early years of the ORLS (1963-1978) and HIPE (1968-1978), covered by ICD7 and ICD8, cases were identified from codes 500 (ICD7 until 1965; bronchitis) and 466 (ICD8, 1965-1978; acute bronchitis and bronchiolitis), and therefore covered acute bronchitis and bronchiolitis without distinguishing them for the period before 1979 . The relevant codes used for asthma admissions were 493 (ICD8 and ICD9) and J45-46 (ICD10).

National Health Service (NHS) admission statistics from 1968 to 1985 were collected on a one-in-ten basis for the whole of England in the HIPE and scaled up to represent all admissions. Admissions from 1989, including day case admissions, were recorded in HES data. Linked HES data from 1999 permitted an analysis of successive admissions for individuals within the population. The ORLS is essentially a fully linked regional subset of HES, collected independently of HIPE and HES, without sampling, from 1963 to 1998 and compiled as a subset from national HES since then. ORLS covers the period between 1985 and 1989 when no HIPE or HES data were collected. ORLS also includes a specialist maternal dataset, collected between 1970 and 1989 with linkage to later years, which includes maternal and perinatal data not routinely collected through HES and has linked data between mother and baby. Infants admitted with bronchiolitis were compared, in this maternal dataset, with all other infants in ORLS born between 1970 and 1989, using methods described elsewhere. ${ }^{19}$ Some data items-for example, maternal smoking, breast feedingwere not covered in all years. Univariable analysis followed by multivariable adjustment was done for significant variables using logistic regression and the stepwise forward method. A cohort of children with bronchiolitis in HES was compared with a cohort of children without a record of bronchiolitis, using analytical methods for disease associations described elsewhere, ${ }^{20}$ to compare the incidence of asthma admissions when aged between 2 and 14 years.

In the trend analyses, hospital admission rates are presented as episode-based and person-based admission rates of cases per 1000 population, for both sexes combined, aged under $<1$ year, expressed as an annual rate. The population denominator for each year and each local area was obtained from mid-year population estimates from the Office for National Statistics (ONS). With the episode-based admission rate, a person admitted several times for the condition is counted as many times as he/ she has admissions. The person-based admission rate counts individuals once, and only once, at the first admission per year in which they were admitted. In the geographical analyses, confined to 1999-2011 when linked person-based data from HES were available, place of residence was determined from the HES record. The boundaries of the Local Government Areas of England were used to map geographical variations in the recorded rates of admissions and the Index of Multiple Deprivation (IMD 2004) score was used as a measure of socioeconomic status for each local area.

The Paediatric Intensive Care Audit Network (PICANet) dataset is a national audit that has collected data on admissions to all PICUs across England since 2002. We used the primary diagnosis for admission and Read codes X100C, XSDOK, H061, H0615, H061z, X100D, Xa0BK, H0612 and XaPOd to identify admissions for bronchiolitis, deaths and length of stay between 2004 and 2012. The PICANet population denominator for each year was estimated from ONS data. Analyses were performed in SAS (trends, mapping, asthma), GraphPad Prism (PICANet) and SPSS (perinatal study).

\section{RESULTS}

\section{Hospital admission rates for bronchiolitis over time}

All-England HIPE and HES data recorded 468138 episodes of admissions for bronchiolitis in infants aged $<1$ year between 1979 and 2011, accounting for 92.6\% of all bronchiolitis admissions in all ages. HES data between 1999 and 2011 recorded 299397 episodes and 259044 infants aged <1 year admitted for bronchiolitis. The mean ratio of episodes to people was 1.16. The annual average episode-based admission rate reached 46.1 (95\% CI 45.6 to -46.6) in 2011, from 6.6 (95\% CI 6.0 to 7.2 ) in 1979 when bronchiolitis discharge codes came into use (a near sevenfold rise in 32 years) (figure 1). The ORLS recorded a total of 25852 episodes and 23319 infants aged $<1$ year admitted for bronchiolitis in this subpopulation of England between 1979 and 2011. The mean ratio of bronchiolitis episodes to number of infants was lower at 1.11 , and 98.2\% of all bronchiolitis admissions were in children aged $<1$ year. Per 1000 infants aged $<1$ year, the annual average episode-based admission rate reached 40.4 (95\% CI 38.5 to 42.3) in 2011, up from 4.5 (95\% CI 3.7 to 5.3) in 1979 (a near ninefold rise in 32 years). The trend could be observed before 1979, from when discharge records began 50 years ago. Between 2004 and 2011, when PICU admissions were recorded, the HES and ORLS datasets recorded an episode-based average annual increment in hospitalisation rates of $1.8 \%$ and $1.6 \%$ respectively. A small, relatively fixed difference between the episode-based and person-based rates of admission emerged from 1995.

\section{Bronchiolitis admissions to PICU over time}

A total of 102126 infants aged 0-5 years were admitted to PICUs between 2004 and 2012. Of the 64066 infants aged $<1$ year, 8172 were diagnosed with bronchiolitis. Infants aged $<1$ year accounted for $93 \%$ of all bronchiolitis admissions and $11.8 \%$ (95\% CI $10.5 \%$ to $13.1 \%$ ) of admissions each year. The estimated PICU admission rate ranged between 1.3 and 1.6 per 1000 infants aged $<1$ year with no consistent trend towards increasing admissions (figure 2). The most frequent age at PICU admission was 1 month and 5083/8172 (62.2\%) of infants were 
Figure 1 Point estimates for the annual average episode and for bronchiolitis per 1000 infants aged $<12$ months from 1979 to 2011, episode-based combined acute bronchitis and bronchiolitis rates from 1965 to 1979 and bronchitis before 1965. Person-based hospital admission rates for males were consistently higher than females (see supplementary material online). $128 \times 63$ mm (300×300 DPI). HES, Hospital Episode Statistics; HIPE, Hospital In-Patient Enquiry; ORLS, Oxford Record Linkage Study. person-based hospital admission rate

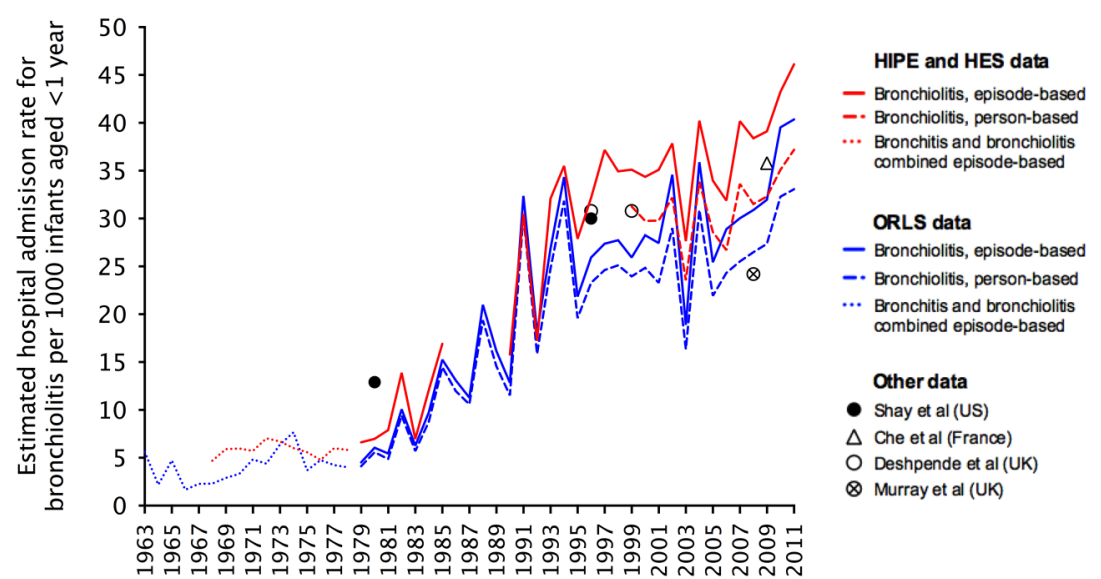

aged 0-2 months. The annual average length of stay for all ages admitted to PICU with bronchiolitis ranged from 5.4 to 6.7 days (mean 6.1 days). Of the bronchiolitis admissions, 158 resulted in death, representing a PICU case-fatality of $1.75 \%$ in infants aged $<12$ months and $4.4 \%$ in infants aged 12 months and older.

\section{Variation in hospital admission rates for bronchiolitis across England}

The mean person-based rate of admissions between 1999 and 2011 was 32.4 per 1000 infants aged $<1$ year $(95 \%$ CI 32.2 to 32.5) and ranged 5.3-fold across the 352 Local Government Areas (figure 3). A positive correlation with higher admission rates for bronchiolitis in areas with higher socioeconomic deprivation was observed (see online supplementary material).

\section{Maternal and perinatal factors associated with hospital} admission for bronchiolitis

Of a total of 243708 infants, 2078 (0.86\%) were admitted to hospital with a diagnosis of bronchiolitis. Of these admissions, $88.7 \%(1852 / 2087)$ were aged $<1$ year (tables 1 and 2). After adjustment of each factor for other significant variables, there were significant associations with year of birth (corroborating the rise in bronchiolitis admission rates over time), low maternal age, low social class, maternal smoking, high parity, twin birth, low birth weight, short gestational age, low birth weight for gestational age, not being breast fed, breech delivery and low Apgar 1 at birth.

\section{Hospital admissions for asthma following bronchiolitis in infancy}

Nine thousand six hundred and twelve children identified in HES were used as the cohort of admissions with bronchiolitis under the age of 2 years. The control cohort used for comparative analysis numbered 46377 children. Of these, 715/9612 (7\%) children from the bronchiolitis cohort had an admission for asthma before age 14 years. The rate ratio for asthma admissions, comparing the bronchiolitis cohort with the control cohort, was 2.8 (95\% CI 2.6 to 3.1$)$.

\section{DISCUSSION}

Data on hospital admission trends for bronchiolitis in the USA, measured per 1000 infants aged <1 year, showed a 2.4-fold rise from 1980 to $1996 .{ }^{17}$ In Canada, between 1981 and 1999, the bronchiolitis admission rate per 1000 infants aged $<6$ months rose 3.5-fold and 2.1-fold in infants aged 6-12 months. ${ }^{18}$
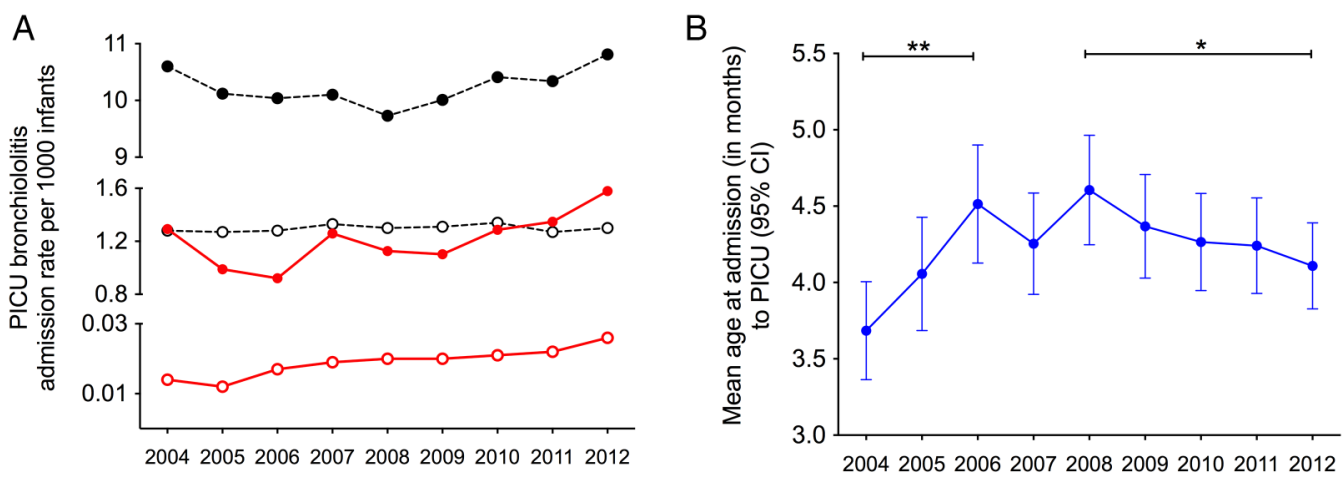

All cause admissions in infants aged $<1$ year
Bronchiolitis admissions in infants aged $<1$ year
All cause admissions in infants aged $1-5$ years
Bronchiolitis admissions in infants aged $1-5$ years

Figure 2 PICU admissions with bronchiolitis and all-causes from 2004 to 2012. (A) All-cause and bronchiolitis admission rates per 1000 infants. (B) Mean age (months with $95 \% \mathrm{Cl}$ ) at admission for bronchiolitis. Between 2004 and 2006 the mean age rose significantly ( ${ }^{* *} p=0.0004$, two-tailed Mann-Whitney). In more recent years the mean age has fallen significantly between 2008 and 2012 ( ${ }^{*} \mathrm{p}=0.04$, two-tailed MannWhitney). $124 \times 62 \mathrm{~mm}(300 \times 300 \mathrm{DPI})$. PICU, paediatric intensive care unit. 
Figure 3 National variation in person-based bronchiolitis hospital admission rates, 1999-2011.

Bronchiolitis admission rates per 1000 infants aged $<1$ year, as analysed using Hospital Episode Statistics, both sexes, mapped using the boundaries of each Local Government Area. $135 \times 173 \mathrm{~mm}(72 \times 72 \mathrm{DPI})$.
Episode-based bronchiolitis admission rates per 1000 infants aged under 1 year, divided by quintiles

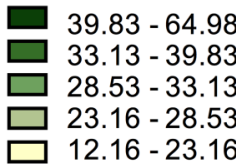

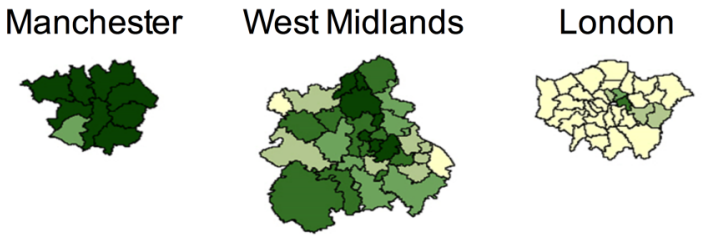

UK data from a single region between 1996 and 1999 recorded an average rate of $30.8^{5}$ and the last estimate from an industrialised nation was single-season data from France, which estimated 35.8 admissions per 1000 infants aged $<1$ year in $2009 .^{21}$ The only all-England estimate recorded an admission rate of 24.2 per 1000 infants aged $<1$ year $^{16}$ using discharge codes in the primary diagnostic position only, which may explain their lower estimated rate for 2007/08 compared with our data.

We have analysed several datasets over a substantial period and consistently found a substantial rise in hospitalisation rates for bronchiolitis in recent years. In contrast, PICU admission rates have changed little from 2004 to 2012 when hospital admission rates rose by an average $1.8 \%$ each year. Although PICU admissions for bronchiolitis have steadily increased as a proportion of all admissions since $2002,{ }^{22}$ these data suggest that the overall rise in hospital admissions reflects changes in the threshold for admission rather than an increase in disease incidence or severity over time. In the early years of the study, ORLS data collection was independent of that in HIPE and the maternity ORLS dataset was collected separately from the 'general hospital' data in the ORLS. These levels of independence increase confidence in the time-trend analyses.

Possible drivers behind changes in recorded hospital admission rates include the increasing prevalence of maternal and perinatal factors that predispose to severe disease, social factors such as parents' expectations, and changes to the way care is provided and used. Improvements in neonatal care have led to an increase in the population at enhanced risk: hospital admission rates are 24.2 for all infants and 47.3 among premature infants per 1000 aged <1 year. ${ }^{162324}$ Even after 36 weeks gestation, our data continue to show an effect of gestational age on the risk of severe disease in single weeks up to weeks 39-41. Before then, each extra week in utero seems to confer added protection against admission with bronchiolitis. In 2003, 7\%$9 \%$ of bronchiolitis admissions were re-admissions ${ }^{5} 25$ and more recent data estimated that $21 \%$ of infants had more than one bronchiolitis admission during the first year of life. ${ }^{16}$ The risk of asthma admission up to the age of 14 years with a preceding history of hospitalisation for bronchiolitis supports previous findings and emphasises the possible wider health consequences of bronchiolitis. ${ }^{9}$

It is noteworthy that overall admission rates in England for children under 15 years of age with lower respiratory tract infections have risen by $40 \%$ in the last decade, together with large increases in paediatric admissions for upper respiratory tract infections, urinary infections and gastroenteritis. ${ }^{26}$ These increases were driven by an increase in admissions of short duration (under $24 \mathrm{~h}$ ). We speculate that major changes in the 
Table 1 Characteristics of the mother and pregnancy associated with the risk of hospital admission for bronchiolitis in infancy

\begin{tabular}{|c|c|c|c|c|}
\hline & $\begin{array}{l}\text { Number of children with bronchiolitis } \\
\text { (total number with each characteristic) }\end{array}$ & $\%$ with bronchiolitis & $\mathrm{p}$ Value & $\begin{array}{l}\text { Adjustment for year of birth, } \\
\text { social class, mother's age, parity, } \\
\text { smoking and sex: OR }(95 \% \mathrm{Cl})\end{array}$ \\
\hline \multicolumn{5}{|l|}{ Year of birth } \\
\hline 1970-1974 & 397 (69 372) & 0.57 & $<0.001$ & \\
\hline 1975-1979 & $273(56768)$ & 0.48 & & \\
\hline 1980-1984 & $530(60446)$ & 0.88 & & \\
\hline 1985-1989 & 887 (57 122) & 1.55 & & \\
\hline Total & 2087 (243 708) & 0.86 & & \\
\hline \multicolumn{5}{|c|}{ Mother's age (years) } \\
\hline $14-19$ & $260(17611)$ & 1.48 & $<0.001$ & 2.36 (1.81 to 3.08$)$ \\
\hline $20-24$ & $729(67447)$ & 1.08 & & $1.42(1.22$ to 1.66$)$ \\
\hline $25-29$ & $648(90467)$ & 0.72 & & $1(1)$ \\
\hline $30-34$ & 325 (49 544) & 0.66 & & 0.87 (0.73 to 1.03$)$ \\
\hline $35-39$ & $106(15423)$ & 0.69 & & 0.63 (0.48 to 0.84 ) \\
\hline $40+$ & 18 (2896) & 0.62 & & 0.70 (0.39 to 1.26$)$ \\
\hline Total & 2086 (243 388) & 0.86 & & \\
\hline \multicolumn{5}{|l|}{ Social class } \\
\hline 1 (high) & $88(22368)$ & 0.39 & $<0.001$ & $1(1)$ \\
\hline 2 & $289(46092)$ & 0.63 & & 1.49 (1.12 to 1.99$)$ \\
\hline 3 & $723(87431)$ & 0.83 & & 1.81 (1.38 to 2.38$)$ \\
\hline 4 & 286 (25 999) & 1.10 & & 2.20 (1.64 to 2.97 ) \\
\hline 5 (low) & 152 (9776) & 1.55 & & 2.34 (1.65 to 3.30$)$ \\
\hline Total & $1538(191666)$ & 0.80 & & \\
\hline \multicolumn{5}{|l|}{ Married } \\
\hline Yes & 1675 (220 269) & 0.76 & $<0.001$ & $1(1)$ \\
\hline No & 411 (22 996) & 1.79 & & $1.13(0.92$ to 1.38$)$ \\
\hline Total & 2086 (243 265) & 0.86 & & \\
\hline \multicolumn{5}{|c|}{ Cigarettes smoked per day } \\
\hline None & $822(103596)$ & 0.79 & $<0.001$ & $1(1)$ \\
\hline $1-4$ & $42(3765)$ & 1.12 & & $1.23(0.84$ to 1.80$)$ \\
\hline $5-14$ & $250(13668)$ & 1.83 & & 1.89 (1.59 to 2.25$)$ \\
\hline $15+$ & 298 (12 991) & 2.29 & & 2.09 (1.77 to 2.48$)$ \\
\hline Total & $1412(134020)$ & 1.05 & & \\
\hline \multicolumn{5}{|l|}{ Parity } \\
\hline 1 & $806(87340)$ & 0.92 & & 1.93 (1.65 to 2.25$)$ \\
\hline 2 & 387 (35 342) & 1.10 & & 2.26 (1.87 to 2.73$)$ \\
\hline $3+$ & $256(18387)$ & 1.39 & & $2.73(2.17$ to 3.43$)$ \\
\hline Total & $2083(243$ 159) & 0.86 & & \\
\hline \multicolumn{5}{|l|}{ Pre-eclampsia } \\
\hline No & 1917 (219 636) & 0.70 & 0.006 & $1(1)$ \\
\hline Yes & $168(24023)$ & 0.87 & & $1.20(0.96$ to 1.50$)$ \\
\hline Total & $2085(243659)$ & 0.86 & & \\
\hline
\end{tabular}

Data from the Oxford Record Linkage Study specialist maternity dataset.

organisation of healthcare in England may have contributed to changing admission rates. One major change has been decreased access to medical assessment outside hospital as a result of both a reduction in out-of-hours care by general practitioners under a reorganised contract from $2004^{27}$ and the introduction of a non-medical protocol-based telephone triage (NHS Direct) in $1999 .^{28}$ The potential for these changes to direct parents to hospital care, where availability of new technology over this period, including oximeters, ${ }^{29}$ may have inadvertently encouraged clinicians to lower the threshold for admission to meet waiting time targets and as a result of clinical protocols. We found that only $25 \%$ of the geographic variation in hospital admission rates could be attributed to socioeconomic deprivation, which is consistent with two other publications of HES data. ${ }^{16}$ The finding of geographical variation and increasing admission rates indicate that there is clinical uncertainty, probably combined with organisational factors, about when to admit a sick child with bronchiolitis.

\section{Limitations of the study}

While the length of the time-period of data collection is a considerable strength of this study, there may have been variation over time in the quality of diagnostic coding and therefore in the accuracy of our data. However, our findings are consistent across different studies both in the UK and elsewhere, suggesting that the large increases in admissions are real. We used PICU admissions as a proxy for severe disease, but other surrogates (such as length of stay in hospital) were not available to infer whether admission rates for cases of mild or moderate disease severity changed over time. Although the overall trend is clear, we noted significant year-to-year variations in hospitalisation rates. Trend data were not available for some factors that may 
Table 2 Characteristics of the delivery and infant associated with the risk of hospital admission for bronchiolitis in infancy

\begin{tabular}{|c|c|c|c|c|}
\hline & $\begin{array}{l}\text { Number children with bronchiolitis } \\
\text { (total number with each characteristic) }\end{array}$ & $\%$ with bronchiolitis & $\mathrm{p}$ Value & $\begin{array}{l}\text { Adjustment for year of birth, } \\
\text { social class, mother's age, parity, } \\
\text { smoking and sex: OR ( } 95 \% \mathrm{Cl})\end{array}$ \\
\hline \multicolumn{5}{|c|}{ Number of babies } \\
\hline 1 & $2009(238311)$ & 0.84 & \multirow[t]{3}{*}{$<0.001$} & $1(1)$ \\
\hline 2 & $76(5348)$ & 1.42 & & 1.86 (1.37 to 2.54$)$ \\
\hline Total & $2085(243659)$ & 0.86 & & \\
\hline \multicolumn{5}{|c|}{ Birth weight of baby $(\mathrm{kg})$} \\
\hline 1-1.499 & $27(1028)$ & 2.63 & \multirow[t]{8}{*}{$<0.001$} & 3.74 (2.32 to 6.01$)$ \\
\hline $1.5-1.999$ & $57(2745)$ & 2.08 & & 2.34 (1.59 to 3.44$)$ \\
\hline $2-2.499$ & $174(10079)$ & 1.73 & & 1.90 (1.50 to 2.41$)$ \\
\hline $2.5-2.999$ & $428(43857)$ & 0.98 & & 1.14 (0.96 to 1.35$)$ \\
\hline $3-3.499$ & $777(95463)$ & 0.81 & & $1(1)$ \\
\hline 3.5-3.999 & $450(68984)$ & 0.65 & & $0.76(0.64$ to 0.89$)$ \\
\hline $4-5.499$ & $163(20661)$ & 0.79 & & 0.90 (0.71 to 1.14$)$ \\
\hline Total & $2076(242817)$ & 0.85 & & \\
\hline \multicolumn{5}{|c|}{ Lowest 10th percentile of birth weight for gestational age } \\
\hline No & 1509 (195 332) & 0.77 & \multirow[t]{3}{*}{$<0.001$} & $1(1)$ \\
\hline Yes & $257(21$ 694) & 1.18 & & 1.34 (1.10 to 1.63$)$ \\
\hline Total & $1766(217026)$ & 0.81 & & \\
\hline \multicolumn{5}{|c|}{ Gestational age (weeks) } \\
\hline $28-36$ & 184 (11 997) & 1.53 & \multirow[t]{10}{*}{$<0.001$} & 2.24 (1.78 to 2.82 ) \\
\hline 37 & $114(10275)$ & 1.11 & & 1.62 (1.23 to 2.14$)$ \\
\hline 38 & $254(27314)$ & 0.93 & & 1.23 (0.99 to 1.52$)$ \\
\hline 39 & $352(45299)$ & 0.78 & & $0.97(0.80$ to 1.19$)$ \\
\hline 40 & 429 (59 596) & 0.72 & & $1(1)$ \\
\hline 41 & $246(42113)$ & 0.58 & & 0.82 (0.66 to 1.02 ) \\
\hline 42 & $105(12811)$ & 0.82 & & 1.04 (0.76 to 1.40$)$ \\
\hline 43 & $32(3603)$ & 0.89 & & 1.21 (0.76 to 1.95$)$ \\
\hline $44+$ & 57 (4742) & 1.20 & & 1.02 (0.67 to 1.55$)$ \\
\hline Total & $1773(217750)$ & 0.81 & & \\
\hline \multicolumn{5}{|l|}{ Infant feeding } \\
\hline Breast & 796 (113 432) & 0.70 & \multirow[t]{3}{*}{$<0.001$} & $1(1)$ \\
\hline Artificial & 758 (49 245) & 1.54 & & 1.35 (1.18 to 1.55$)$ \\
\hline Total & 1554 (162 677) & 0.96 & & \\
\hline \multicolumn{5}{|c|}{ Caesarean delivery } \\
\hline No & $1895(224350)$ & 0.84 & \multirow[t]{3}{*}{0.026} & $1(1)$ \\
\hline Yes & 183 (18 248) & 1.00 & & 1.35 (1.03 to 1.53$)$ \\
\hline Total & 2078 (242 598) & 0.86 & & \\
\hline \multicolumn{5}{|l|}{ Presentation } \\
\hline Vertex & 1510 (153 258) & 0.99 & \multirow[t]{4}{*}{0.28} & $1(1)$ \\
\hline Other & $12(1528)$ & 0.79 & & 1.37 (1.03 to 1.81$)$ \\
\hline Breech & $76(6578)$ & 1.16 & & $0.76(0.36$ to 1.60$)$ \\
\hline Total & 1598 (161 364) & 0.99 & & \\
\hline \multicolumn{5}{|c|}{ Apgar score at $1 \mathrm{~min}$} \\
\hline $1-7$ & 437 (45 935) & 0.95 & \multirow[t]{4}{*}{0.015} & 1.29 (1.01 to 1.66$)$ \\
\hline $8-9$ & 1288 (146 938) & 0.88 & & 1.07 (0.86 to 1.34$)$ \\
\hline 10 & 209 (28 015) & 0.75 & & $1(1)$ \\
\hline Total & 1934 (220 888) & 0.88 & & \\
\hline \multicolumn{5}{|c|}{ Apgar score at $5 \mathrm{~min}$} \\
\hline $1-7$ & 34 (2758) & 1.23 & \multirow[t]{4}{*}{0.16} & 1.07 (0.67 to 1.72 ) \\
\hline $8-9$ & $130(11$ 133) & 1.17 & & 1.30 (1.05 to 1.62$)$ \\
\hline 10 & $1360(134510)$ & 1.01 & & $1(1)$ \\
\hline Total & $1524(148401)$ & 1.03 & & \\
\hline \multicolumn{5}{|l|}{ Sex } \\
\hline Male & 1216 (125 358) & 0.97 & $<0.001$ & $1(1)$ \\
\hline Female & 871 (118 344) & 0.74 & & 0.74 (0.66 to 0.84$)$ \\
\hline Total & 2087 (243 702) & 0.86 & & \\
\hline
\end{tabular}

Data from the Oxford Record Linkage Study specialist maternity dataset. 
have influenced trends in bronchiolitis rates: these include other conditions that predispose to developing severe bronchiolitis, and demographic factors such as ethnicity. ${ }^{31}$

\section{Conclusions}

Hospital admissions for bronchiolitis in England are increasing and exceed recent estimates from similar industrialised nations. PICU admission rates have changed little over the same period and indicate a need to examine the threshold used for hospital admission and explore the medical and social factors behind the rising admission rates. The high rate of emergency admissions, lack of universal and cost-effective preventative measures and the magnitude of disease incidence make bronchiolitis a major priority for control; these factors also provide a strong rationale for development of strategies for RSV prevention through vaccination.

Acknowledgements We would like to thank all the staff in the participating hospitals who collected data for PICANet. We are grateful to the UK Paediatric Intensive Care Society for continued support and to the members of the PICANet Steering Group and Clinical Advisory Group who are listed on the PICANet website http://www.picanet.org.uk/participants.html. The HES data for 1989-2011 were provided by the Health and Social Care Information Centre (which has been unable to supply data from 2012, following a general embargo on its supplying HES data to academic researchers).

Contributors AJP and MJG instigated, designed and supervised the study. CAG drafted the manuscript for publication. Data were collected and analysed by CAG, AG, RCP, PM, CS and MJG. DY designed the software for analysis of HIPE and HES data. All authors provided critical revision to the manuscript, had access to all of the data and took responsibility for the integrity of the data and accuracy of data analysis.

Funding This work was supported by several sources. Building of the ORLS, HIPE and HES datasets was funded by the National Institute for Health Research (grant RNC/035/02). MJG is part-funded by Public Health England. PICANet is funded by the National Clinical Audit \& Patient Outcomes Programme, administered by the Healthcare Quality Improvement Partnership (HQIP); Welsh Health Specialised Services Committee; NHS Lothian/National Service Division NHS Scotland; the Royal Belfast Hospital for Sick Children; National Office of Clinical Audit Ireland (NOCA) and HCA International. Role of the Funders and Sponsors: This was an investigator-controlled study. The design and conduct of the study, collection and management of data, manuscript preparation and review, manuscript approval and the decision to submit the manuscript for publication was made independently and exclusively by the authors.

Competing interests AJP has previously conducted clinical trials of vaccines on behalf of Oxford University funded by industry, but does not receive any personal payments from them. AJP is chair of the UK Department of Health's (DH) Joint Committee on Vaccination and Immunisation (JCVI), but the views expressed in this manuscript do not necessarily represent the views of JCVI or DH.

Ethics approval Approval for research using the anonymised datasets of the ORLS, HIPE and HES was obtained from the Central and South Bristol Research Ethics Committee (04/Q2006/176). Collection of personally identifiable data by PICANet was approved by the Patient Information Advisory Group (now the NHS Health Research Authority Confidentiality Advisory Group) and ethical approval granted by the Trent Medical Research Ethics Committee (05/MRE04/17+5).

Provenance and peer review Not commissioned; externally peer reviewed.

Open Access This is an Open Access article distributed in accordance with the terms of the Creative Commons Attribution (CC BY 4.0) license, which permits others to distribute, remix, adapt and build upon this work, for commercial use, provided the original work is properly cited. See: http://creativecommons.org/ licenses/by/4.0/

\section{REFERENCES}

1 Hasegawa K, Tsugawa Y, Brown DF, et al. Trends in bronchiolitis hospitalizations in the United States, 2000-2009. Pediatrics 2013;132:28-36.

2 Miller EK, Gebretsadik T, Carroll KN, et al. Viral etiologies of infant bronchiolitis, croup and upper respiratory illness during 4 consecutive years. Pediatr Infect Dis $J$ 2013:32:950-5.
3 Glezen WP, Taber LH, Frank AL, et al. Risk of primary infection and reinfection with respiratory syncytial virus. Am J Dis Child 1986;140:543-6.

4 Hall CB, Weinberg GA, Iwane MK, et al. The burden of respiratory syncytial virus infection in young children. N Engl J Med 2009:360:588-98.

5 Deshpande SA, Northern V. The clinical and health economic burden of respiratory syncytial virus disease among children under 2 years of age in a defined geographical area. Arch Dis Child 2003;88:1065-9.

6 Tsolia MN, Kafetzis D, Danelatou K, et al. Epidemiology of respiratory syncytial virus bronchiolitis in hospitalized infants in Greece. Eur J Epidemiol 2003;18:55-61.

7 Hasegawa K, Pate BM, Mansbach JM, et al. Risk factors for requiring intensive care among children admitted to ward with bronchiolitis. Acad Pediatr 2015;15: 77-81.

8 Sigurs N, Aljassim F, Kjellman B, et al. Asthma and allergy patterns over 18 years after severe RSV bronchiolitis in the first year of life. Thorax 2010;65:1045-52.

9 Regnier SA, Huels J. Association between respiratory syncytial virus hospitalizations in infants and respiratory sequelae: systematic review and meta-analysis. Pediatr Infect Dis J 2013;32:820-6.

10 Blanken MO, Rovers MM, Molenaar JM, et al. Respiratory syncytial virus and recurrent wheeze in healthy preterm infants. N Engl J Med 2013;368:1791-9.

11 Szabo SM, Gooch KL, Bibby MM, et al. The risk of mortality among young children hospitalized for severe respiratory syncytial virus infection. Paediatr Respir Rev 2013;13:S1-8.

12 Lozano R, Naghavi M, Foreman K, et al. Global and regional mortality from 235 causes of death for 20 age groups in 1990 and 2010: a systematic analysis for the Global Burden of Disease Study 2010. Lancet 2012;380:2095-128.

13 Nair H, Nokes DJ, Gessner BD, et al. Global burden of acute lower respiratory infections due to respiratory syncytial virus in young children: a systematic review and meta-analysis. Lancet 2010;375:1545-55.

14 Sommer C, Resch B, Simoes EA. Risk factors for severe respiratory syncytial virus lower respiratory tract infection. Open Microbiol J 2011;5:144-54

15 Boyce TG, Mellen BG, Mitchel EF Jr., et al. Rates of hospitalization for respiratory syncytial virus infection among children in medicaid. J Pediatr 2000;137:865-70.

16 Murray J, Bottle A, Sharland M, et al. Risk factors for hospital admission with RSV bronchiolitis in England: a population-based birth cohort study. PLOS ONE 2014;9: e89186.

17 Shay DK, Holman RC, Newman RD, et al. Bronchiolitis-associated hospitalizations among US children, 1980-1996. JAMA 1999;282:1440-6.

18 Langley JM, LeBlanc JC, Smith B, et al. Increasing incidence of hospitalization for bronchiolitis among Canadian children, 1980-2000. J Infect Dis 2003;188:1764-7.

19 Goldacre MJ, Wotton CJ, Maisonneuve JJ. Maternal and perinatal factors associated with subsequent meningococcal, Haemophilus or enteroviral meningitis in children: database study. Epidemiol Infect 2014;142:371-8.

20 Gold J, Goldacre R, Maruszak H, et al. HIV and lower risk of multiple sclerosis: beginning to unravel a mystery using a record-linked database study. I Neurol Neurosurg Psychiatry 2015;86:9-12.

21 Che D, Nicolau J, Bergounioux J, et al. Bronchiolitis among infants under 1 year of age in France: epidemiology and factors associated with mortality. Arch Pediatr 2012;19:700-6.

22 Paediatric Intensive Care Audit Network. http://www.picanet.org.uk/Audit/ Annual-Reporting/PICANet_Annual_Report_2013_summary.pdf

23 Weisman L. Populations at risk for developing respiratory syncytial virus and risk factors for respiratory syncytial virus severity: infants with predisposing conditions. Pediatr Infect Dis J 2003;22(2 Suppl):S33-7; discussion S37-9.

24 Wen SW, Smith G, Yang Q, et al. Epidemiology of preterm birth and neonatal outcome. Semin Fetal Neonatal Med 2004;9:429-35.

25 Fjaerli HO, Farstad T, Bratlid D. Hospitalisations for respiratory syncytial virus bronchiolitis in Akershus, Norway, 1993-2000: a population-based retrospective study. BMC Pediatr 2004;4:25.

26 Gill PJ, Goldacre MJ, Mant D, et al. Increase in emergency admissions to hospital for children aged under 15 in England, 1999-2010: national database analysis. Arch Dis Child 2013;98:328-34.

27 National Audit Office. The provision of out-of-hours care in England. National Audit Office, 2006.

28 Cooper DL, Smith GE, Edmunds WJ, et al. The contribution of respiratory pathogens to the seasonality of NHS Direct calls. J Infect 2007:55:240-8.

29 Schuh S, Freedman S, Coates A, et al. Effect of oximetry on hospitalization in bronchiolitis: a randomized clinical trial. JAMA 2014:312:712-18.

30 Cheung CR, Smith $\mathrm{H}$, Thurland $\mathrm{K}$, et al. Population variation in admission rates and duration of inpatient stay for bronchiolitis in England. Arch Dis Child 2013;98:57-9.

31 O'Donnell DR, Parslow RC, Draper ES. Deprivation, ethnicity and prematurity in infant respiratory failure in PICU in the UK. Acta Paediatr 2010;99:1186-91. 